\title{
Making Connections Across a Four-Year Project-Based Curriculum: ePort- folios as a Space for Reflection and Integrative Learning
}

\section{Dr. Chrysanthe Demetry, Worcester Polytechnic Institute}

Dr. Chrysanthe Demetry is associate professor of Mechanical Engineering and director of the Morgan Teaching \& Learning Center at Worcester Polytechnic Institute. Her teaching and scholarship interests focus on materials science education, K-12 engineering outreach, gender equity in STEM, and intercultural learning in experiential education abroad. As director of the Morgan Center at WPI since 2006, Dr. Demetry coordinates programs and services fostering excellence and innovation in teaching at WPI and supports course-based and program-level assessment of student learning outcomes.

\section{Ms. Paula Quinn, Worcester Polytechnic Institute}

Through her role as Associate Director for the Center for Project-Based Learning at Worcester Polytechnic Institute, Paula Quinn works to improve student learning in higher education by supporting faculty and staff at WPI and at other institutions to advance work on project-based learning. She believes projectbased learning holds significant potential for increasing the diversity of students who succeed in college and who persist in science, technology, engineering, and math (STEM) fields, and she views her work with the Center as contributing to education reform from the inside out. She holds an M.A. in Developmental Psychology from Clark University and a B.A. in Psychology from Case Western Reserve University. Her background includes working in the field of education evaluation, where she focused primarily on the areas of project-based learning; STEM; pre-literacy and literacy; student life; learning communities; and professional development. She has worked on projects whose funding sources have included the National Science Foundation, the Institute of Education Sciences, and the U.S. Department of Education.

\section{Dr. Stephen James Kmiotek P.E., Worcester Polytechnic Institute}

As a Professor of Practice, my focus is to bring my 30 years of experience in the chemical and environmental industries to the undergraduate classes and curriculum development. My focus through most of my career has been on Chemical Process Safety, Environmental, Health and Safety, and, Air Pollution Engineering. These fields draw on virtually every part of chemical engineering, but they also draw heavily on other disciplines, including social justice and law, leading to programs that are heavily multidisciplinary. Also, my experience has spanned many types of industries, from traditional chemical companies, to electronics and microelectronics, to pulp and paper, metal foundries, and even wineries and breweries. The result is a rich, integrated background on which to draw to help mentor the engineering leaders of the future. 


\title{
Making Connections Across a Four-Year Project-Based Curriculum: ePortfolios as a Space for Reflection and Integrative Learning
}

\begin{abstract}
The systematic use of reflection and integrative learning across experiences in the curriculum and co-curriculum has often been neglected in engineering education, yet these processes are essential for deep and transferable learning. This paper reports on the use of ePortfolios to provide a mechanism for reflection and integrative learning in a four-year, project-based curriculum. Student use of ePortfolios was introduced in the context of the National Academy of Engineering's Grand Challenges Scholars Program. As a pilot in the program's first year at Worcester Polytechnic Institute (WPI), 15 seniors created showcase ePortfolios as an ungraded activity, using a retrospective approach to gather evidence from both academic and extracurricular experiences to demonstrate five competencies. Student interviews revealed that they valued creating ePortfolios and that the process was inherently reflective and created opportunities for integrative learning. However, evidence of integrative learning and reflection in the content of the ePortfolios was inconsistent, ranging from very little to significant. Student learning — and skill at communicating understanding of their learning - could be enhanced by ensuring a scaffolded and recursive process for ePortfolio creation that incorporates ongoing dialogue with mentors and peers.
\end{abstract}

\section{Introduction}

We learn by doing, if we reflect on what we have done.

- John Dewey

Authentic experiences combined with reflection and continual integration across time and contexts are essential for deep, transferable learning, development of expertise, and ethical development. Ambrose [1] identifies these elements as core principles from the learning sciences that should be foundations for high quality undergraduate engineering education. A well-designed curriculum, among other things, has "authentic experiential learning opportunities to put theory into practice in the real world" and "opportunities for reflection to connect thinking and doing" across all four years [1, p. 17]. Many studies have also shown that experiences outside of the formal curriculum, such as participation in clubs and organizations, can have a strong effect on learning and development in the college years [2]-[4]. Although integration of authentic experiences in engineering curricula is now fairly common, the systematic use of reflection and integrative learning across the curriculum and co-curriculum remains neglected [1], [5].

Given a curriculum with disciplinary and interdisciplinary project requirements, a strong program in the humanities and arts, on-campus and off-campus project experiences inside and outside of STEM in all four years of study, combined with 
extensive involvement in extracurricular activities, all undergraduates at WPI engage in a rich set of learning experiences in a variety of contexts. However, historically there have been no formal means to prompt students to reflect on their learning experiences, make meaning of them, or make connections between them. This paper reports on the use of ePortfolios to provide that mechanism and space for reflection and integrative learning.

This specific use of ePortfolios occurs in the context of a National Academy of Engineering Grand Challenges Scholars Program (GCSP). To be designated as a Grand Challenge Scholar at WPI, students create an ePortfolio that demonstrates their competencies in five areas: research ability, interdisciplinary and multidisciplinary perspectives, innovation and entrepreneurship mindset, global and intercultural competence, and social responsibility. We envision that, ultimately, students will begin creating working portfolios in their first or second year to both plan and reflect, and then curate a showcase ePortfolio in their senior year. As a pilot in the program's first year, a small cohort of seniors was recruited to reflect back on their four years and create showcase ePortfolios.

In this paper we provide an overview of the importance of reflection and integrative learning in higher education and the uses and efficacy of ePortfolios to foster those processes. We explain the core elements of the curriculum at WPI and how the Grand Challenge Scholars Program was implemented in its pilot year. Analysis of portfolios showed the wide range of learning experiences, inside and outside of the formal curriculum, that students drew upon, and also a wide range of quality in reflection and integrative learning as evidenced in the portfolios. Interviews with students revealed that some of the value of the ePortfolio derived from the process that students were directed to use to identify material for inclusion, because it compelled them to engage in reflection and created opportunities for integrative learning to occur. Overall, this paper contributes to the engineering education literature by showing the value of four-year integrative ePortfolios, and what might be necessary to obtain more uniformly positive evidence of benefits.

\section{Literature review}

Experience, and particularly reflection on experience, are central to numerous theories of learning, including those of John Dewey [6], Donald Schön [7], David Kolb [8], and Jack Mezirow [9]. In the last decade, the engineering education community has given increasing attention to the importance of reflection through such initiatives as the Consortium to Promote Reflection in Engineering Education (CPREE) [10]. As part of that work, Turns, Shroyer, Lovins, and Atman [11] described a conceptual framework for the types of knowledge that may be constructed from reflection activities: professional knowledge, personal knowledge (e.g., identity work), and preparedness knowledge. Yancey [12] notes that in addition to making knowledge through reflection, students can learn outcomes-based self-assessment and develop as reflective practitioners, 
synthesizing multiple sources of evidence. Reflection also has been identified as an essential element of high quality project-based learning [13].

Closely related to some aims of reflection, integrative learning is "an understanding and a disposition that students build across the curriculum and cocurriculum, from making simple connections among ideas and experiences to synthesizing and transferring learning to new, complex situations within and beyond the campus" [14]. Others have defined integrative learning as the ability to learn across contexts and over time, with intentionality [15]. Learners actively seek to connect their present learning to their past understandings and how they might use new knowledge and abilities in the future. In contrast, many students' experience in higher education involves moving through a curriculum with the goal of passing courses and other experiences that seem to be discrete and unrelated.

An electronic portfolio is a tool that supports both integrative learning and reflection. In 2016, ePortfolios were identified as a "high impact practice" (HIP) by the American Association of Colleges and Universities based on evidence of their benefit for student learning and student success [16]. A study by the Inter/National Coalition for Electronic Portfolio Research also found evidence of efficacy: ePortfolio reflection was directly related to student success at multiple institutions [12], using measures such as course completion rates, retention rates, and student engagement survey data. To construct ePortfolios, learners are asked to select, reflect on, and curate evidence of learning. An ePortfolio may be constructed within a particular course, for a project or applied learning experience, within a curriculum or program of study, for general education, or across four years of study.

Electronic portfolios are gaining traction in engineering education. Practitioners and researchers have discussed using ePortfolios as a reflective space for graduate students to track their development as scholars and teachers [17], a tool for assessment of ABET learning outcomes and professional skills [18], a mechanism for engineering identity development [19], preparation for lifelong learning [20], and to support learning in course-based projects [21]. However, most of these studies have been confined to using ePortfolios in or across particular courses or the formal curriculum. Use of portfolios that integrate curricular and extracurricular experiences across four years can be found in honors programs, liberal arts, and other professional studies [22], [23], but seem less common in engineering education.

This study adds to the literature by examining how engineering and science undergraduates in a project-based curriculum connect both curricular and cocurricular experiences to the development of competencies across four years. Moreover, we investigate the evidence of reflection and integrative learning in such portfolios and what students reveal they learn from the process of creating one. 


\section{Institutional and program context}

\section{Curricular and extracurricular learning experiences}

WPI is a STEM-intensive institution, with $99 \%$ of undergraduates receiving a bachelor's degree in a field of science or engineering. The project-based curriculum, degree requirements, and extracurricular activity at WPI provide students with a rich set of learning experiences:

First Year Project (elective): 6 credit hours, interdisciplinary problem-based course, team-taught by faculty in STEM and non-STEM disciplines. Team projects result in proposed solutions for a self-chosen, context-specific instance of a global problem.

Humanities \& Arts Capstone (requirement): 18 credit hours including 3 credit capstone project in depth area chosen by student. Capstone may be original creative work or performance, or original research on a self-proposed question or topic.

Interdisciplinary Project (requirement): 9-12 credit hours, not a course. Student teams from multiple majors address an interdisciplinary, open-ended problem at the interface of technology, society, and human need. Projects are typically for a real client at an off-campus location.

Major Project (requirement): 9 credit hour design or research experience, not a course. Historically within major, but a growing number are completed in multidisciplinary teams, with a mix of student-initiated and industrysponsored projects.

More than $75 \%$ of WPI students complete at least one of the required projects in an off-campus immersive experience at one of $40+$ project centers around the globe. In addition, many courses include projects of various types, and many students are highly engaged in extracurricular activities including Engineers Without Borders, Engineering Ambassadors, multiple groups focused on innovation and entrepreneurship, athletics, fraternities and sororities with strong philanthropic missions, leadership positions in professional societies and residence life, among others.

At WPI, discussion about reflection, integrative learning, and ePortfolios intensified during a strategic planning process in 2014-15. Faculty, students, staff, and alumni all saw the need or opportunity to help students think about their education more broadly than their major, to help them discover or create themebased or competency-based "connective threads" in multiple contexts across four years. They also wanted to help students integrate curricular, co-curricular, and extracurricular learning, to make meaning of their learning experiences, make 
their learning more visible, and to communicate their learning from experiences more effectively. For example, anecdotal evidence suggested that some students did not see or communicate the value of their global project experience to prospective employers since the project was not related to their major. In the words of Donald Schön, too many students "have the experience but miss the meaning" [7, p. 280].

One outcome of the strategic planning process was investment in an ePortfolio platform to foster reflection and integrative learning under the theme of "major and a mission." Faculty, staff, and students could access support to use the platform, and leaders of multiple initiatives experimented with the use of ePortfolios within courses, in projects, and in student organizations. One such initiative was the Grand Challenge Scholars Program.

\section{Grand Challenges Scholars Program and ePortfolio development}

The National Academy of Engineering created the Grand Challenges Scholars Program (GCSP) framework for engineering education in 2008, in an effort to produce engineering graduates who could effectively address "Grand Challenges" of the $21^{\text {st }}$ century [24], which cut across themes of sustainability, health, security, and joy of living. The program premise is that engineering curricula should provide students with experiences that help them develop five competencies: research /creativity, multidisciplinary, business/entrepreneurship, multicultural, and social consciousness.

Institutions propose the details of their own GCSP program within the broad NAE framework. The program at WPI was approved in 2017. Since all of the ingredients for the program were already in place, no new curricular elements were created. We aimed for low barriers to participation for both students and program directors. Therefore, participating in the program is not credit-bearing, there are no grades, no strict requirements, and a relatively small time commitment. The only requirement of the program is to attend some group networking/reflection sessions and to create an ePortfolio that provides evidence of the five competencies in the context of grand challenges. Longer term, the vision is that students will join by the end of their sophomore year. In addition to reflecting on their experience to curate a showcase ePortfolio in their senior year, the students will create a working portfolio in the earlier years and be guided through both reflection and planning to select learning experiences with the grand challenges and/or competencies in mind.

In the inaugural year (2017-18), the program was piloted with 19 seniors identified through a database search who met the following criteria: a) STEM major; b) business or entrepreneurship minor or member of a club related to innovation and entrepreneurship; and c) completed a global project. These students were invited to join the inaugural program and help refine its implementation. Their academic and extracurricular choices had already been made by this time, so their participation primarily involved creating a showcase 
ePortfolio structured around the five GCSP competencies. The ePortfolio was described as, first, a mechanism to document their attainment of the competencies for the NAE and internal and external reviewers, but also as a mechanism to showcase their work to a variety of potential audiences. Example of these audiences that we provided included potential employers or graduate schools and professional and social colleagues. It also served as a journal for their personal reflection and growth.

We provided some scaffolding for the ePortfolio development process. A twohour program launch meeting was held in October 2017. First, students were introduced to the 14 Grand Challenges and the broader cross-cutting themes, and began to identify those that their interests and work touched upon. In rotating small groups, they were then asked to brainstorm about each of the five competencies: How could each be measured or demonstrated? The session concluded by asking them to create a map to make connections between their learning experiences and the GCSP competencies. They were encouraged to reflect back on courses and projects, work in a minor, activities in clubs and organizations, leadership positions, summer jobs and internships, and volunteer work.

Over the next several months, students were invited to an open lab session to introduce them to the ePortfolio platform and to group meetings to share their work in progress. Attendance at these meetings was not mandatory and typically ranged between 5-8 students. We provided a simple ePortfolio template, with one page dedicated to each competency, but we encouraged students to be creative and make it their own. Question prompts guided students to define the competency, identify at least one experience and artifact that best exemplified their competency in each of the five areas, and then to reflect either in a written statement or with multiple media on how that competency was developed through the experience(s), showing links between experience and learning.

Students earned the distinction of Grand Challenge Scholar if they completed an ePortfolio by April of 2018 that drew upon at least five experiences to show evidence of the five program competencies. Those who completed portfolios were recognized at an academic awards ceremony, received a special cord to wear at commencement, and received a certificate of accomplishment from the NAE.

\section{Methods}

\section{Research questions}

This exploratory study was designed to address the following questions:

1) What mix of academic and extracurricular experiences did students use as they reflected upon and documented the Grand Challenge competencies? 
2) When students used a "look back" approach to create an ePortfolio in their senior year, to what extent did they convey evidence of integrative learning and reflection?

3) What did students learn, if anything, in the process of creating ePortfolios?

\section{Study participants}

Fifteen of the original 19 students completed their ePortfolios, and 14 of those consented to participate in this study. The students' majors included mechanical engineering (3), robotics engineering (3), biomedical engineering (2), chemical engineering (2), aerospace engineering (1), civil engineering (1), computer science (1), and mathematics (1). Nine were female, and five were male. We did not collect information about race or ethnicity.

\section{Analysis of ePortfolios}

Two authors independently reviewed each ePortfolio to audit the learning experiences that each participant referenced for each competency. At this stage we did not assess the depth or quality of evidence they provided. We classified each experience as a particular curricular experience (credit-bearing course inside or outside the major, project requirement) or as an extracurricular experience. Extracurricular experiences were non-credit bearing and included industry or research internships, clubs and organizations, athletics, fraternity and sorority activities, volunteer work, and other personal initiatives. One of the authors then reconciled both reviews and compiled the mix of learning experiences for the whole cohort.

Following a norming session that used the ePortfolios of two students, the three authors independently rated each ePortfolio for the level of reflection and integrative learning evident for each of the Grand Challenge competencies. To assess reflection, we used the "Reflection" component of the AAC\&U Foundations and Skills for Lifelong Learning VALUE Rubric [14]. To assess integrative learning we used the "Connections to Experience" component of the AAC\&U Integrative Learning VALUE Rubric [14], after adapting the descriptors to be relevant to the competencies. Each of the rubrics uses a 5-level descriptive scale from benchmark (1) to capstone (4), with a zero assigned to work that does not provide evidence for the benchmark description.

An inter-rater reliability (IRR) analysis was conducted for each type of assessment to determine the extent to which raters consistently assessed the degree to which students meaningfully reflected and the degree to which students connected their experiences to academic knowledge. For each assessment, kappa was computed for each coder pair, then averaged across all three pairs to provide a single index of IRR [25]. The resulting kappas for both the reflection assessment $(\kappa=0.53)$ and integrative learning assessment $(\kappa=0.52)$, indicated moderate agreement [26]. Across all three raters, ratings never differed by more than one 
level for each measurement (student, competency, and reflection or integrative learning). For reporting in this paper, averages are presented.

Interview methods and analysis

Six students volunteered to be interviewed regarding their experience in the GCSP. The semi-structured interviews asked students what their participation did for them as learners, what they learned through GCSP, what aspects of GCSP helped them learn. (Additional questions that are not related to the purposes of this paper are not reported here.)

One of the authors with experience in assessment, evaluation, and qualitative methods conducted all of the interviews, which were later transcribed. She identified patterns in the responses through an inductive search using an iterative process that involved multiple listenings of interview recordings and multiple readings of transcripts.

\section{Results}

\section{Students drew almost equally on curricular and extracurricular experiences}

Study participants addressed their development of the five GCSP competencies by drawing on a wide range of curricular and extracurricular experiences, as shown in Table 1. Most of their ePortfolio pages (52 of 70) identified multiple experiences for each competency. Among all of the experiences utilized, about $55 \%$ were curricular and $45 \%$ extracurricular. Among the academic experiences, participants drew most heavily on an interdisciplinary project that most completed outside of the U.S., especially to showcase global competency and multidisciplinary perspectives. Many discussed their major capstone project to document their creative research or design abilities. Participants also reflected on courses both inside and outside their major, many with embedded projects. Courses in business and entrepreneurship were most commonly cited. Fewer students connected their course or project work in the humanities and arts to the development of the five competencies. For the social consciousness competency, participants drew to a much greater extent on extracurricular experiences than on learning experiences in the formal curriculum.

\section{Portfolios varied widely in depth of reflection and integrative learning}

Evidence of reflection and integrative learning in the content of the ePortfolios was inconsistent, ranging from very little to significant, as shown in Figures 1 and 2 , respectively. Despite the inconsistencies, 80 percent of all measurements achieved at least a rating of 2, namely that the student demonstrated at least some level of reflection and integrative learning beyond a superficial level. Following is an excerpt from Student C's entry about research ability, which was rated 4 for reflection and 2 for integrative learning: 


\begin{tabular}{|c|c|c|c|c|c|c|c|c|c|c|c|}
\hline \multirow[b]{2}{*}{ Competency } & \multicolumn{6}{|c|}{ Curricular experiences $^{\mathrm{a}}$} & \multicolumn{4}{|c|}{ Extracurricular experiences } & \multirow[t]{2}{*}{$\begin{array}{c}\% \\
\text { Curricular }\end{array}$} \\
\hline & FYP & HUA & IP & MP & $\begin{array}{l}\text { Course/ } \\
\text { project } \\
\text { in } \\
\text { major }\end{array}$ & $\begin{array}{c}\text { Course/ } \\
\text { project } \\
\text { outside } \\
\text { major } \\
\end{array}$ & Internship $^{\mathbf{b}}$ & Club/org ${ }^{c}$ & Volunteer & Other $^{\text {d }}$ & \\
\hline Research/creativity & 3 & 1 & 1 & 10 & 4 & & 3 & 3 & & & $76 \%$ \\
\hline Multidisciplinary & 3 & & 7 & & 6 & 2 & 3 & 7 & & & $64 \%$ \\
\hline Business/entrepreneur & & & 2 & 3 & & 11 & 5 & 8 & & 3 & $50 \%$ \\
\hline Global & & 1 & 12 & 2 & & 2 & 1 & 2 & & 6 & $65 \%$ \\
\hline Social consciousness & & 3 & & 1 & 1 & 1 & & 13 & 5 & 2 & $23 \%$ \\
\hline Total $^{\mathrm{e}}$ & 6 & 5 & 22 & 16 & 11 & 16 & 12 & 33 & 5 & 11 & \\
\hline \multicolumn{12}{|c|}{$\begin{array}{l}\text { Notes: } \\
\text { a FYP= interdisciplinary first-year project-based } \\
\text { project (off-campus); MP= capstone project in }\end{array}$} \\
\hline \multicolumn{12}{|c|}{$\mathrm{b}$ Includes not-for-credit undergraduate research } \\
\hline \multicolumn{12}{|c|}{${ }^{\mathrm{C}}$ Includes athletics, professional societies, fraternities and sororities, in addition to clubs and organizations } \\
\hline
\end{tabular}


Figure 1: Reflective Learning Ratings

으

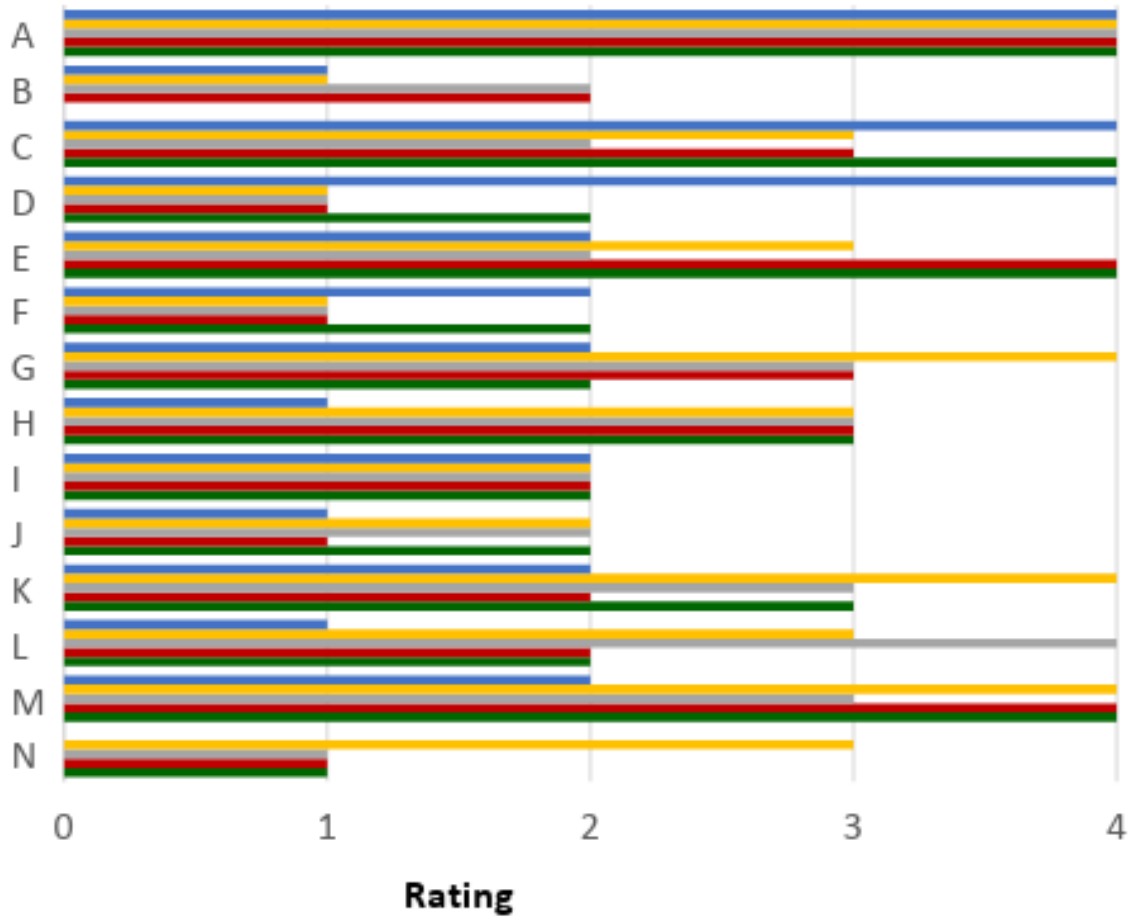

-Social Global/Multi I\&E Multidisciplinary Research

\section{Figure 2: Integrative Learning Ratings}

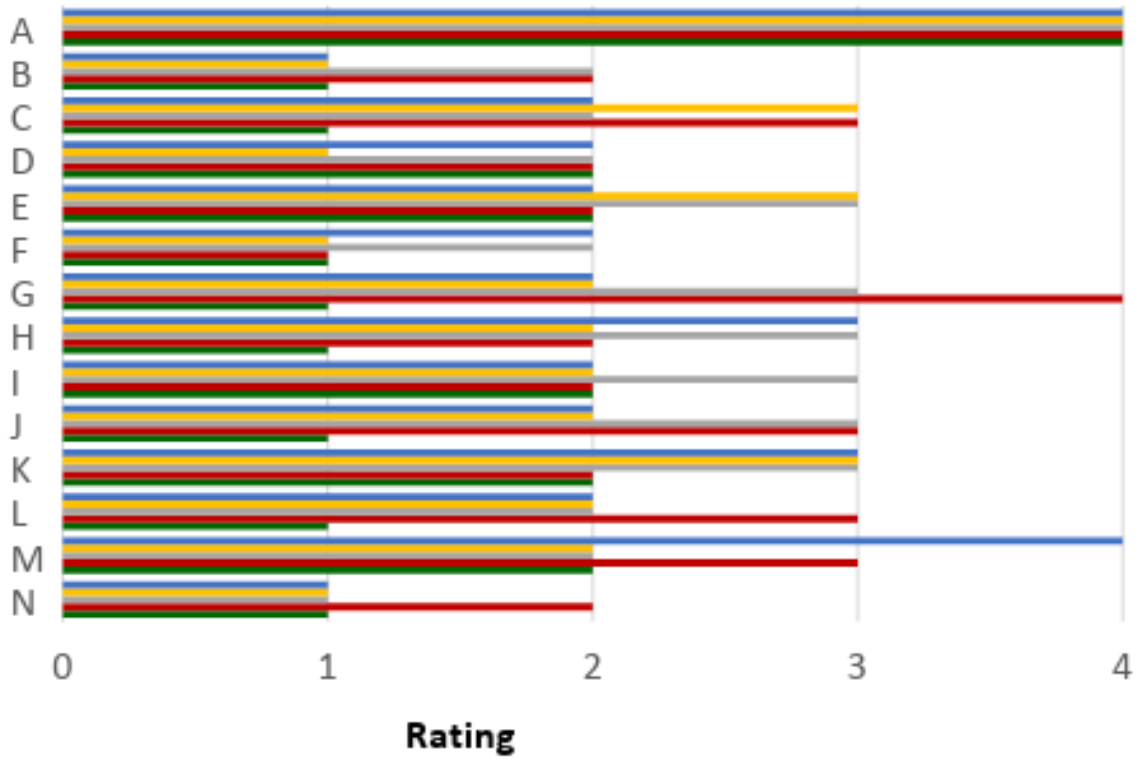

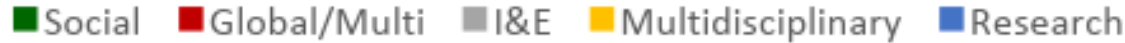


This (co-curricular laboratory) experience altered my view of the research industry. I was enamored and became aware that research is an ongoing process, and some dedicate their entire lives and career to such specific topics... Breaking down and troubleshooting problems... was a significant part of my learning experience. I gained unique technical skills...that morphed into the building blocks for projects in my future.

In general, portfolios showed more evidence of reflection than integrative learning. Fifty-seven percent of the portfolios showed the "capstone" level of reflection (4) for at least one competency, whereas only 21 percent showed the capstone level of integrative learning for at least one competency.

Ten of the 14 portfolios were rated at level 3 or higher for at least one competency in either reflection or integrative learning. An example of an advanced level of integrative learning and reflection, with a rating of 4 in each, is exemplified by Student A's entry about research ability and creativity. He integrated and synthesized experiences from a ballroom dance club and being a disk jockey (to free his mind, develop capacity to be creative, and disconnect from fear of rejection), three design classes, an internship, and his major project. Following is a short excerpt:

I was able to apply both of these skills (creativity and research) in conjunction during my internship where I had to design a test fixture.... During this time, I realized that innovation is not a linear process. The steps to pursuing a design is iterative, and creativity can be utilized simultaneously with research. I also learned that there will always be stages of failure. Learning how to overcome these challenges, thus gaining support from real engineers in the field helped build both my creative confidence and design thinking.

Only one ePortfolio was assessed at the capstone level (4) for all competencies for both reflection and integrative learning. Although no ePortfolio rated 1 or less for all competencies for either reflection or integrative learning, two ePortfolios were rated no greater than 2 for all competencies, for both reflection and integrative learning.

Students saw value of the ePortfolios

Analysis of interviews revealed that student perspectives were broadened in a number of ways through creation of the ePortfolio. The ways they were broadened differed depending on which of the following two purposes the ePortfolio served: 1) as a prompt for students to demonstrate - through reflection via writing - their achievement in the five competencies of the GCSP or 2) as an object that serves as a persistent record of those reflections and other evidence that is available to share and be reviewed by others or by the ePortfolio creators, themselves. 
Student interviews conveyed that the process of ePortfolio developmentinvolving writing and reflection within a structure requiring carefully-considered evidence in support of each of the five competency areas-helped students connect their work to competency areas they had not previously considered. This student's comment conveys this well:

...when I was doing a project prior [to GCSP], I was looking at it from one perspective. But then, when it came to Grand Challenge scholars, I said, "All right, I did this project, but hey, this met three out of the five core competencies." ... so I probably had more perspective on it from different angles, looking back on the projects, and learning from it that way ... and kind of taking that challenge to pursue other projects and other things in life through the multiple perspectives, versus just the one I was focusing on at the time.

And she elaborated, implying that the process of ePortfolio creation in the GCSP had established in her foundations for lifelong learning:

...so I think that ... one of the purposes of the whole program is to become this Grand Challenge scholar and solve the world's problems, one step at a time, and I think, through learning how to see, how to view a problem from multiple perspectives, you're better off finding the solution....[S] for me, the learning experience, while I didn't necessarily learn while doing the projects because it was more of a back-end type of thing, looking back at the projects, I think learning how to achieve various milestones through these multiple perspectives is really important and ... I think that's one thing I've gained from this program itself.

The following comment from another student reinforces that the process encourages integrative learning. She explained how she altered her career path because the GCSP made her see her situation from a different perspective:

I was involved in Engineers Without Borders, had my computer science major, had some research experience with computer science, but I honestly didn't really see the overlap between the two things that I did, because EWB was focused on something completely outside of my major, but it was helping people. Whereas computer science was ... kind of academically what I'm really interested in. And so, I think, looking at the five different competencies in the program, I realized the overlap ... within research and multi-disciplinary, multicultural, ... social consciousness, all of those competencies-have been developed by both, kind of, tracks, and so I wanted to, kind of-I think, 
through the program-I wanted to put them together, see how they fit, in a way. And I don't think I ever really thought about that before [Grand Challenges].

When asked what it was about GCSP that caused her to develop that awareness, she identified the ePortfolio as the mechanism:

I think it was, honestly, creating ... the writing portion of the ePortfolio.... So, there was a structure ... a loose structure, provided for us, about what to include in the ePortfolio, and it was organized by the five different competencies, and you were challenged to find evidence throughout your college career ... to ... demonstrate you were proficient in each of those competencies. And there were so many different projects that could fit into each of those competencies, and at the end was a section about thoughts for the future.... And so I kind of based my thoughts for the future on the main themes that the Grand Challenge program puts forth....

This student conveys how her perspective expanded from viewing work as an absolute object or thing in and of itself to something whose meaning could be altered depending on the context in which it was being discussed:

...I think one of the really cool things ... we did is the online portfolio.... That's one way to kinda showcase everything you've done, more so than just a resume and having bullet points on the project. And so, being able to integrate each thing that I do and being able to-I think it's motivation to be able to talk about it. If I could say, you know, in my next job- "I worked on this project, not only did I learn the technical side of things, but here are other things that I could talk about. "-I think that's more beneficial than anything. So getting that view overall will be something I carry with me, just as, like, a personal benefit.

When serving as a communication vehicle for GCSP thought work, the ePortfolios served to broaden student thinking in terms of both reflection on the work of others and reflection on their own work. Because the ePortfolio platform gave students access to one another's GCSP work, students saw the perspectives of their peers with regard to how they addressed the competencies, students saw ways of making meaning that differed from their own, and they had opportunities to contrast creative expression and visual choices of others with their own. In addition, though, it was valuable to students that their own ePortfolios existed as a reference for themselves. Value was gained in the present by using the ePortfolio to understand the process of identity development of the self, as indicated by one student in this way: 
I think that reflective component, personally, was probably the most valuable to me, being able to look back and think about what I've done over the past four years here at [university], and how those pieces kind of fit together into making me, kinda, the person I am now, as I'm ready to leave [university] and go out into the real world.... I don't think, like, these competencies are, like, the endall be-all, what defines you, but ... I do think that all of the experiences that I've had, that I've documented, have kinda played a part into shaping what I wanna do in the future.

This same student anticipated that the ePortfolio would be valuable when referred to in the future, as well, when he will have a different perspective:

“... what I do like about the portfolio is it's there now, it's not going anywhere. And ... it'll be there for people to see in the future.... and I could go back and look at it in the future and see where my work was there, and perhaps compare, like, with what I'm doing in the future, and see how I've changed ... over time."

\section{Discussion and implications}

Analyses revealed that creating an ePortfolio was a useful learning tool for students. Most student ePortfolios did indeed convey that they reflected on authentic experiences, and the contents of 12 of the 14 student ePortfolios demonstrated a high level of reflection and/or integrative learning in at least one competency. Findings from interviews revealed, though, that the selection and decision-making process that students had to engage in to determine the relevance of their work and experience to each of the competencies made reflection an inherent part of the process. It is not unreasonable to assume, then, that reflection and integrative learning occurred at rates higher than were evident through analyses of the ePortfolios.

The wide variation in the quality of integrative learning and reflection that we observed in the portfolios could be explained by multiple factors. Unlike many of the ePortfolio assignments in the literature, this was an elective, ungraded activity that intentionally had no formal requirements. For example, we did not direct students to connect with multiple experiences for each competency, and we did not ask them to utilize rubrics for reflection or integrative learning. With no strict deadlines or expectations and a busy senior year, some students procrastinated and did not benefit from a recursive process. Other practitioners have noted the challenge of motivating students to invest time and effort in ePortfolios when they are ungraded and non-compulsory [20].

Moreover, some students may have intentionally limited their reflection or the number of connections because of the audience they had in mind. Questions of audience arose during some group meetings: Am I doing this mostly for myself or 
do I really want to share it with potential employers or graduate schools? How much are people really going to want to read? We also note that this initial cohort was specifically requested to reflect back on their past experiences, recognizing that they entered the GCSP program toward the end of their undergraduate studies. As expected, the quality and depth of reflection generally exceeds the quality and depth of integrative learning, potentially due to the fact that this cohort of students was not directly encouraged to preplan and integrate their experiences proactively in the context of the GCSP.

Turns, Cuddihy \& Guan [21] also found variation in student experiences within the same course-based ePortfolio assignment, characterizing them as significant, muted, or limited. They recommended that student experiences could be enhanced by providing them with guidance for finding artifacts and facilitating peerviewing of portfolios. Indeed, in this pilot year of our GCSP program, some students created their portfolios largely as solo endeavors, while others attended optional meetings with peers and mentors during the development stage. In the interviews, those who were regular attendees often commented on the value of seeing the work of their peers.

Based on the findings of this study, we have identified two primary areas for program improvement and use of ePortfolios. We noted that few students integrated their work in the humanities and arts, whereas perspectives from the liberal arts are valuable or even essential to address societal grand challenges in an ethical manner. In addition, very few students utilized academic work to document their development of social consciousness or social responsibility, and few discussed social responsibility directly in the context of being an engineer or scientist. At the same time, these seniors also had not planned their four years with the grand challenges or competencies in mind. A key goal for further development of the program is to help students see how their work in the humanities and arts can be selected to provide broader perspectives on societal grand challenges. In fact, WPI has been participating with a group of institutions, with support of the Teagle Foundation, to better integrate the liberal arts with engineering.

We also believe that student learning — and skill at communicating understanding of their learning — could be enhanced by ensuring a scaffolded, recursive process for ePortfolio creation that uniformly incorporates ongoing dialogue with mentors and peers. From a study of student portfolios, Rickards and Guilbault [27] noted the importance of providing students with multiple, iterative opportunities to review their learning and develop their reflective practice in different contexts and across time. We anticipate that once students in the program start developing their ePortfolios in earlier years, and reflect regularly on their experiences, that evidence of the depth of reflection and extent of integrative learning is likely to increase, giving us more confidence that our students are learning in deep and transferable ways. 


\section{References}

[1] S.A. Ambrose, "Undergraduate Engineering Curriculum: The Ultimate Design Challenge,” The Bridge, vol. 43, no. 2, pp. 16-23, 2013. Available: https://www.nae.edu/19582/Bridge/81221/81228.aspx

[2] A.W. Astin, What matters in college: Four critical years revisited. San Francisco, CA: Jossey-Bass, 1993.

[3] E.T. Pascarella and P.T. Terenzini, How college affects students: A third decade of research (Vol. 2). San Francisco, CA: Jossey-Bass, 2005.

[4] C.J. Finelli, M.A. Holsapple, E. Ra, R.M. Bielby, B.A. Burt, D.D. Carpenter, and J.A. Sutkus, “An Assessment of Engineering Students' Curricular and Co-Curricular Experiences and Their Ethical Development," Journal of Engineering Education, vol. 101, no. 3, pp. 469-494, 2012.

[5] J.A. Turns, B. Sattler, K. Yasuhara, J. Borgford-Parnell, and C.J. Atman, "Integrating reflection into engineering education," in Proceedings of the ASEE Annual Conference and Exposition. 2014. (2014, June).

[6] J. Dewey, Experience and education. New York, NY: Kappa Delta Pi, 1938.

[7] D. Schön, The reflective practitioner: How practitioners think in action. New York, NY: Basic Books, 1983.

[8] D. A. Kolb, Experiential learning: Experience as the source of learning and development. Englewood Cliffs, NJ: Prentice-Hall, Inc., 1984.

[9] J. Mezirow, Learning as Transformation: Critical Perspectives on a Theory in Progress. San Francisco, CA: Jossey-Bass Publishers, 2000.

[10] Consortium to Promote Reflection in Engineering Education (2014). Available at http://cpree.uw.edu/

[11] J.A. Turns, K.E. Shroyer, M.T.L. Lovins, and C.J. Atman, "Understanding Reflection Activities Broadly," in Proceedings of the American Society for Engineering Education Annual Conference and Exhibition. 2017.

[12] K.B. Yancey, "Reflection and electronic portfolios: Inventing the self and reinventing the university," in Electronic portfolios 2.0: Emergent research on implementation and impact, D. Cambridge, B. Cambridge, and K. Yancey, Eds. Sterling, VA: Stylus Publishing, 2009, pp. 5-16.

[13] Buck Institute for Education (2015). Gold Standard PBL: Essential Project Design Elements. Available at http://www.bie.org/ 
[14] Association of American Colleges and Universities (AAC\&U) (n.d.) Integrative Learning VALUE Rubric and Lifelong Learning Value Rubric, VALUE Rubric Development Project. Available at https://www.aacu.org/value/rubrics

[15] C. Reynolds and J. Patton, Leveraging the ePortfolio for Integrative Learning: A Faculty Guide to Classroom Practices for Transforming Student Learning. Sterling, VA: Stylus, 2014.

[16] C.E. Watson, G.D. Kuh, T. Rhodes, T.P. Light, and H.L. Chen, "ePortfolios-The eleventh high impact practice," International Journal of ePortfolio, vol.6, no. 2, pp. 65-69, 2016.

[17] M.V. Svyantek and L.D. McNair, "Tricks of the Trade: Using Digital Portfolios and Reflective Practices to Develop Balanced Graduate Student Professional Identities," in American Society for Engineering Education, 2015. June 14-17, Seattle, WA. Conference Proceedings. 2015

[18] L. McNair, M. Paretti, M.L. Wolfe, and T. Knott, "Defining and assessing the ABET professional skills using ePortfolio," in ASEE Annual Conference and Exposition, Conference Proceedings. Proceedings. 2006

[19] M. Eliot and J. Turns, "Constructing professional portfolios: Sense-making and professional identity development for engineering undergraduates," Journal of Engineering Education, vol. 100, no. 4, pp. 630-654, 2011.

[20] E. Heinrich, M. Bhattacharya, and R. Rayudu, R., "Preparation for lifelong learning using ePortfolios,” European Journal of Engineering Education, vol. 32, no. 6, pp. 653-663, 2007.

[21] J. Turns, E. Cuddihy, and Z. Guan, "I thought this was going to be a waste of time: How portfolio construction can support student learning from project-based experiences," Interdisciplinary Journal of Problem-Based Learning, vol. 4, no. 2, 2010. [Online]. Available: https://doi.org/10.7771/1541-5015.1125 2010

[22] C.R. Corley and J. Zubizarreta, "The Power and Utility of Reflective Learning Portfolios in Honors," Journal of the National Collegiate Honors Council, vol. 13, no. 1, pp. 63-76, 2012.

[23] T.W. Knott, V.K. Lohani, O.H. Griffin, G.V. Loganathan, G.T. Adel, and T.M. Wildman "Bridges for Engineering Education: Exploring ePortfolios in Engineering Education at Virginia Tech," Washington: American Society for Engineering Education. 2004.

[24] National Academy of Engineering (n.d.) Grand Challenges Scholars Program. Available: http://www.engineeringchallenges.org/ GrandChallengeScholarsProgram.aspx 
[25] R.J. Light, "Measures of response agreement for qualitative data: Some generalizations and alternatives," Psychological Bulletin, vol. 76, no. 5, pp. 365-377, 1971. Available: http://dx.doi.org/10.1037/h0031643

[26] J.R. Landis, and G.G. Koch, "The measurement of observer agreement for categorical data," Biometrics, vol. 33, no. 1, pp. 159-174, 1977. Available: https://www.jstor.org/stable/pdf/2529310.pdf

[27] W. H. Rickards and L. Guilbault, "Studying student reflection in an electronic portfolio environment," Electronic portfolios, vol. 2, pp. 17-28, 2009. 